\title{
Implementation of an Online Database for Chemical Propulsion Systems
}

\author{
David B. Owen, II \\ Chemical Propulsion Information Analysis Center, Columbia, MD, 21044 \\ Patrick S. McRight ${ }^{\dagger}$ \\ NASA Marshall Space Flight Center, Huntsville, AL, 35812 \\ and \\ Eric H. Cardiff ${ }^{\ddagger}$ \\ NASA Goddard Space Flight Center, Greenbelt, MD 20771
}

\begin{abstract}
The Johns Hopkins University, Chemical Propulsion Information Analysis Center (CPIAC) has been working closely with NASA Goddard Space Flight Center (GSFC); NASA Marshall Space Flight Center (MSFC); the University of Alabama at Huntsville (UAH); The Johns Hopkins University, Applied Physics Laboratory (APL); and NASA Jet Propulsion Laboratory (JPL) to capture satellite and spacecraft propulsion system information for an online database tool. The Spacecraft Chemical Propulsion Database (SCPD) is a new online central repository containing general and detailed system and component information on a variety of spacecraft propulsion systems. This paper only uses data that have been approved for public release with unlimited distribution. The data, supporting documentation, and ability to produce reports on demand, enable a researcher using SCPD to compare spacecraft easily, generate information for trade studies and mass estimates, and learn from the experiences of others through what has already been done. This paper outlines the layout and advantages of SCPD, including a simple example application with a few chemical propulsion systems from various NASA spacecraft.
\end{abstract}

\section{Introduction}

$\mathrm{T}$ HE goal of this database project is to capture historical data that are of interest for a variety of uses including, but not limited to, investigating design precedents; anchoring mass estimates and design approaches for concept and trade system studies; comparing propulsion system architectures and schematics; examining precedents and best practices; and understanding lessons learned. A fundamental objective of the Spacecraft Chemical Propulsion Database (SCPD) is to capture propulsion specific design and operational knowledge that is too frequently lost. SCPD contains data tables displayed in a tabular Web interface, bibliographic references, and design documentation on a variety of spacecraft propulsion systems. These systems may be Earth-orbiting satellites, interplanetary spacecraft, upper stage systems, interplanetary Landers, or transfer vehicles, including both human-rated and robotic spacecraft. Most of the spacecraft in SCPD have already flown, but the database may contain data for fully integrated and tested systems that have not yet flown. The searchable database is currently limited to U.S.

\footnotetext{
"Research Engineer; Chemical Propulsion Information Analysis Center, The Johns Hopkins University, 10630 Little Patuxent Pkwy, Suite 202, Columbia, MD 21044; Member.

${ }^{\dagger}$ Chief; Spacecraft and Auxiliary Propulsion Systems Branch, Mail Stop ER23, NASA MSFC, Huntsville, AL, 35812; Member.

${ }^{\ddagger}$ Propulsion Engineer; Propulsion Branch, Building 11, Room E135, Mail Stop 597, NASA GSFC, Greenbelt, MD 20771; Senior Member.
}

Distribution Statement A: Approved for public release, distribution is unlimited.

American Institute of Aeronautics and Astronautics 
spacecraft with one or more chemical, liquid, or gas propulsion systems. There is potential for long-term future expansions of SCPD to include solid, electrical, and micro propulsion systems.

\section{SCPD Overview}

By capturing the spacecraft propulsion system information in a database format, the material is presentable to the propulsion community through a useful, accessible, and secure method. SCPD is presented online as one of many tools in the secure Chemical Propulsion Information Network (CPIN). Using the tabular Web interface, the user can quickly and easily navigate between the home page, search, search hits, browse, and reports pages. The search page provides the user with a variety of drop-down menus that allow the user to specify the search criteria. The criteria can be as specific as the satellite's name or as broad as a particular propellant. The options include the propellant, pressurant gas, manufacturer of a component, propellant tank mass, filter rating, engine, number of engines, and engine performance criteria. A full list of search options is shown in Figure 1. Searching without entering any search criteria will display all records in the database.

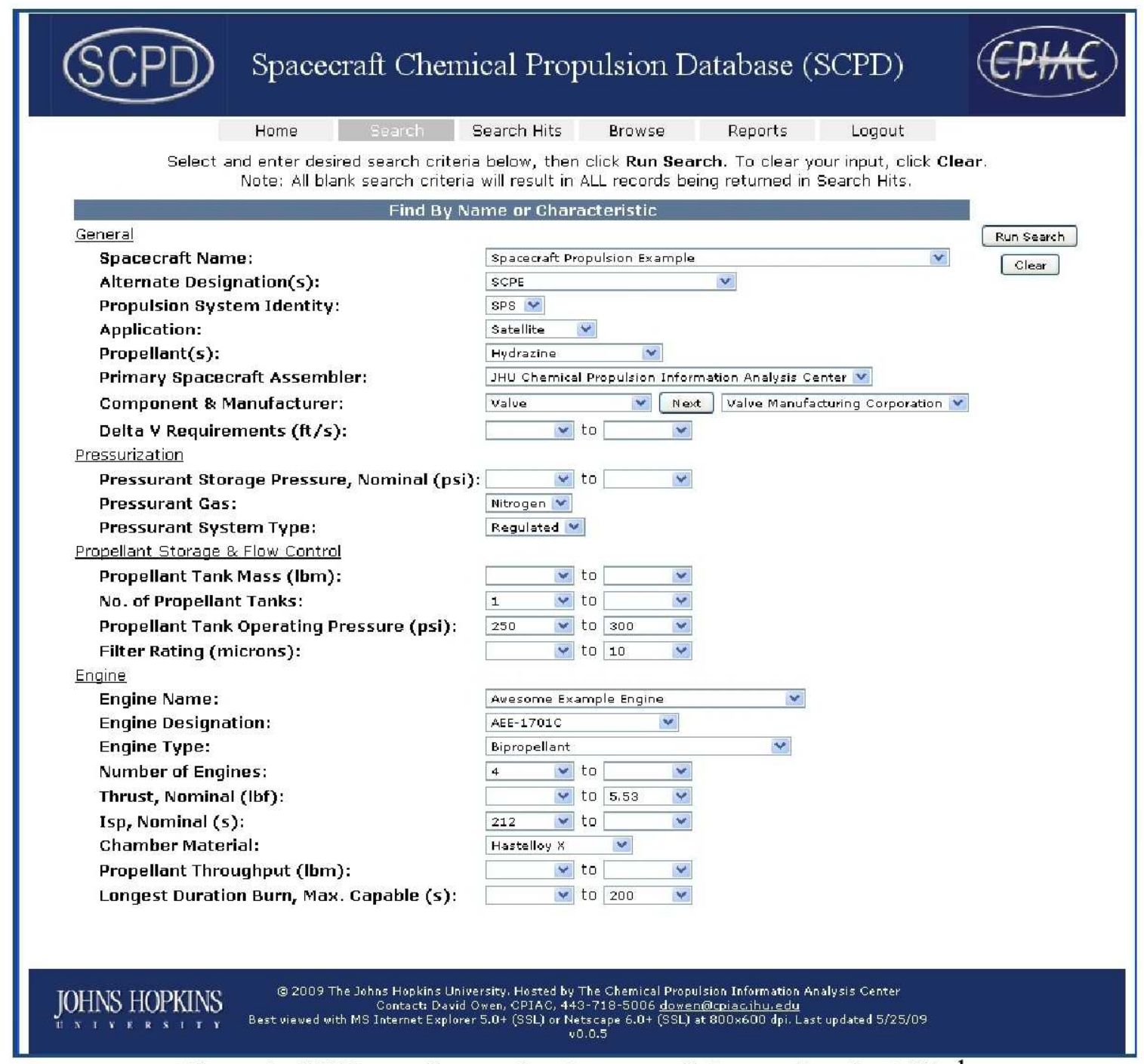

Figure 1. SCPD search page showing a search for a notional satellite. ${ }^{1}$

The results of a search are displayed on a search hits tab (Figure 2) in a chart format. The chart provides the following information for each propulsion system: Spacecraft Name, Propulsion System Identity, and Alternative Designation. There is a check box next to each system; the box is checked by default. The user may click on a check box to deselect or reselect a system. The user can then filter out the systems that are not checked using the "Filter List" button. Once filtered, the "Filter List" function instead reads "Unfilter List." At any point one can 
"unfilter" to show all of the search hits. Filtering is useful for browsing and generating reports containing only the selected systems.

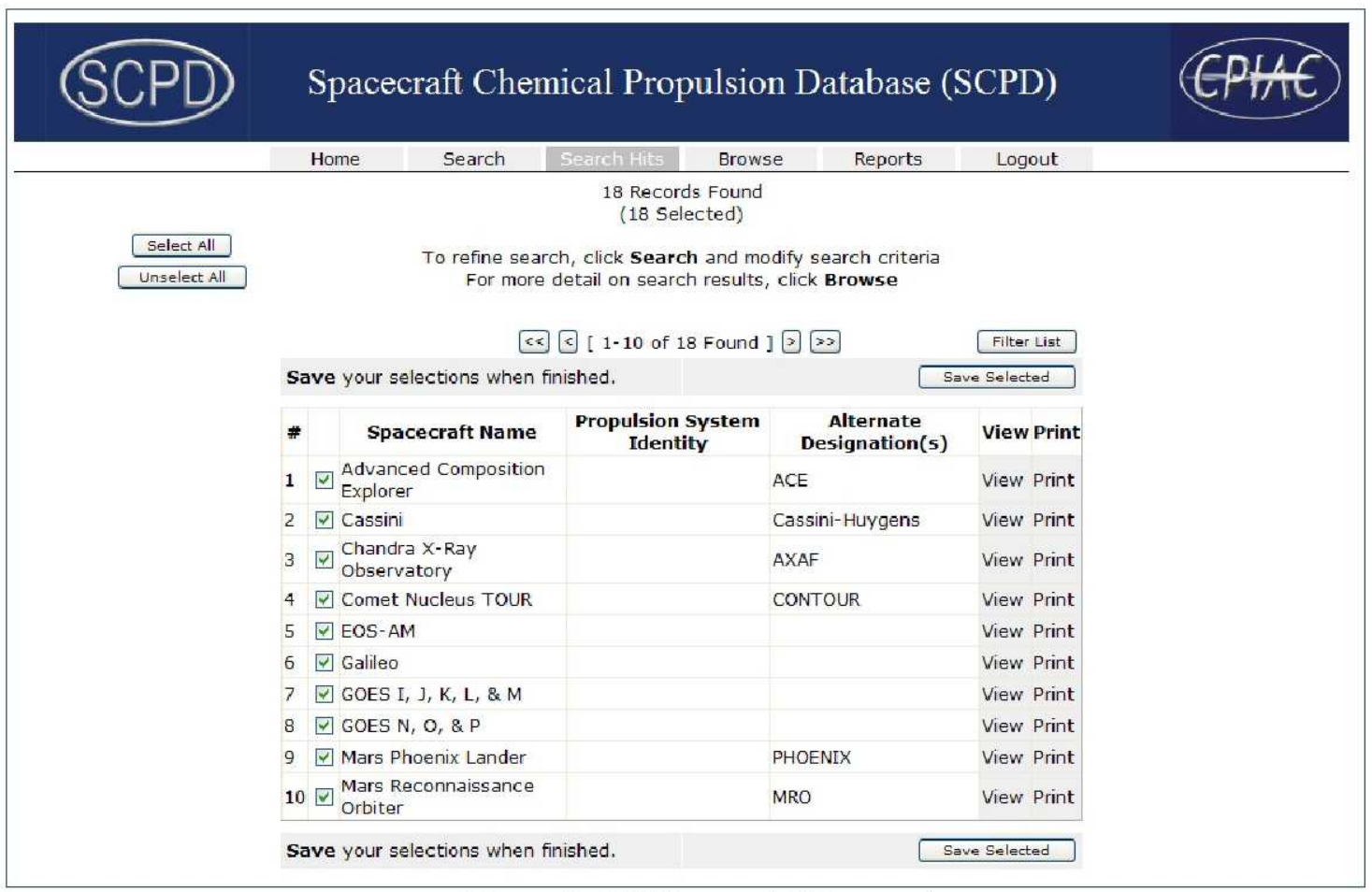

Figure 2. SCPD search hits page. ${ }^{1}$

The engineering data for the spacecraft are displayed in the browse pages (Figure 3). The user can navigate to the browse page from the search hits page by either clicking on the "Browse" tab or by selecting the "View" link next to a spacecraft. Clicking on the browse tab will enable the user to start browsing at the first record in the search results. Clicking on the "view" link will take the user directly to the propulsion system that has been selected to view. The "print" function opens a rich text format data sheet report for the one spacecraft that was printed.

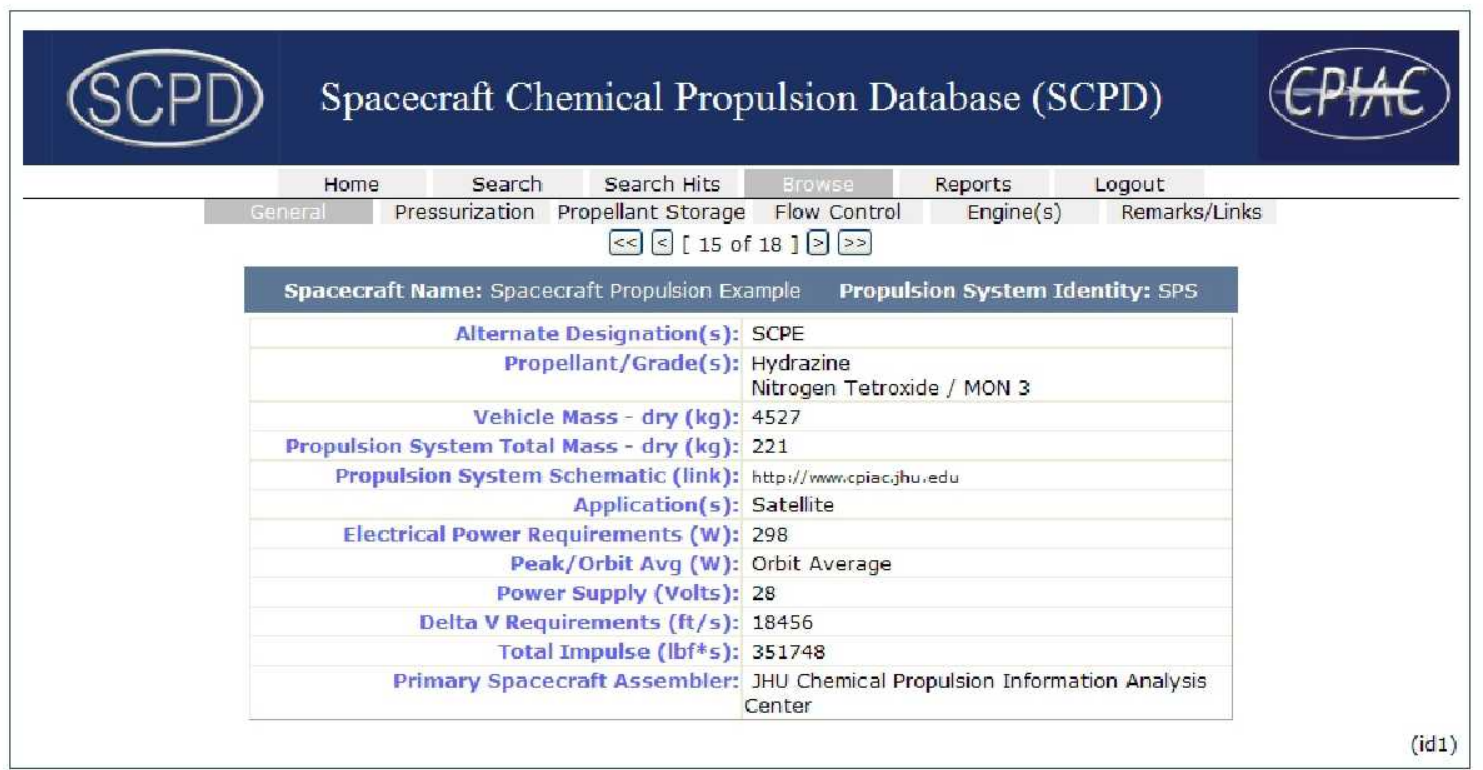

Figure 3. SCPD browse page, general sub tab. ${ }^{1}$ The data show is from a notional satellite. 
Within the browse page (Figure 3), the spacecraft data are broken down into propulsion subsystems. A sub level of tabs is used for easy navigation between data tables. The data tables contain general spacecraft information and detailed propulsion system information on the pressurization subsystem, propellant subsystem, flow control or feed subsystem, engines and engine performance. Arrow icons $\triangle$ located immediately below the tabs allow the user to navigate easily between different spacecraft. This application allows the user to quickly navigate between various satellites, which in turn permit users to quickly compare different spacecrafts' propulsion subsystems.

Table 1. SCPD Browse Sub Tab Overview.

\begin{tabular}{|ll|}
\hline General & Spacecraft Overview \\
Pressurization & Pressurization subsystem, Regulators, Pressure Transducers \\
Propellant Storage & Propellant Tanks \\
Flow Control & Feed System, Filters, Valves, Orifices, Pyrotechnic Devices \\
Engine(s) & Engines, Engine Materials, Engine Performance \\
Remarks/Links & Comments, Links, Reference List \\
\hline
\end{tabular}

Table 1 shows a synopsis of the six sub tabs under the browse function. The general tab provides an overview of the propulsion system with data items such as the propellants, dry mass, applications, and spacecraft assembler. The pressurization tab provides information on the pressurant system and tanks, pressure relief system, regulators, and pressure transducers. The propellant storage tab's information revolves around the propellant tanks. The flow control tab has general feed system information as well as information on filters, valves, orifices, and pyrotechnic devices. The engine(s) tab (Figure 4) provides an overview of the thrusters, some detailed material information, and the performance specifications in an "engine modes" table. The remarks/links tab provides additional notes about the system, links to useful sources, and, when possible, a list of references, some of which are available for immediate download.

In the pressurization, propellant storage, and flow control tabs, when multiple components are used in a system, they are all combined into a single table for each component type. For example, if five different types of valves are used in a system, then the valves table will list all five valves in the same table for easy comparison. This is different for the engine(s) tab. In the case of multiple engines of different types being used in a system, the information for one engine is followed by that engine's performance specification, with the second engine type and its performance table shown below that, and so on for all engine types. 


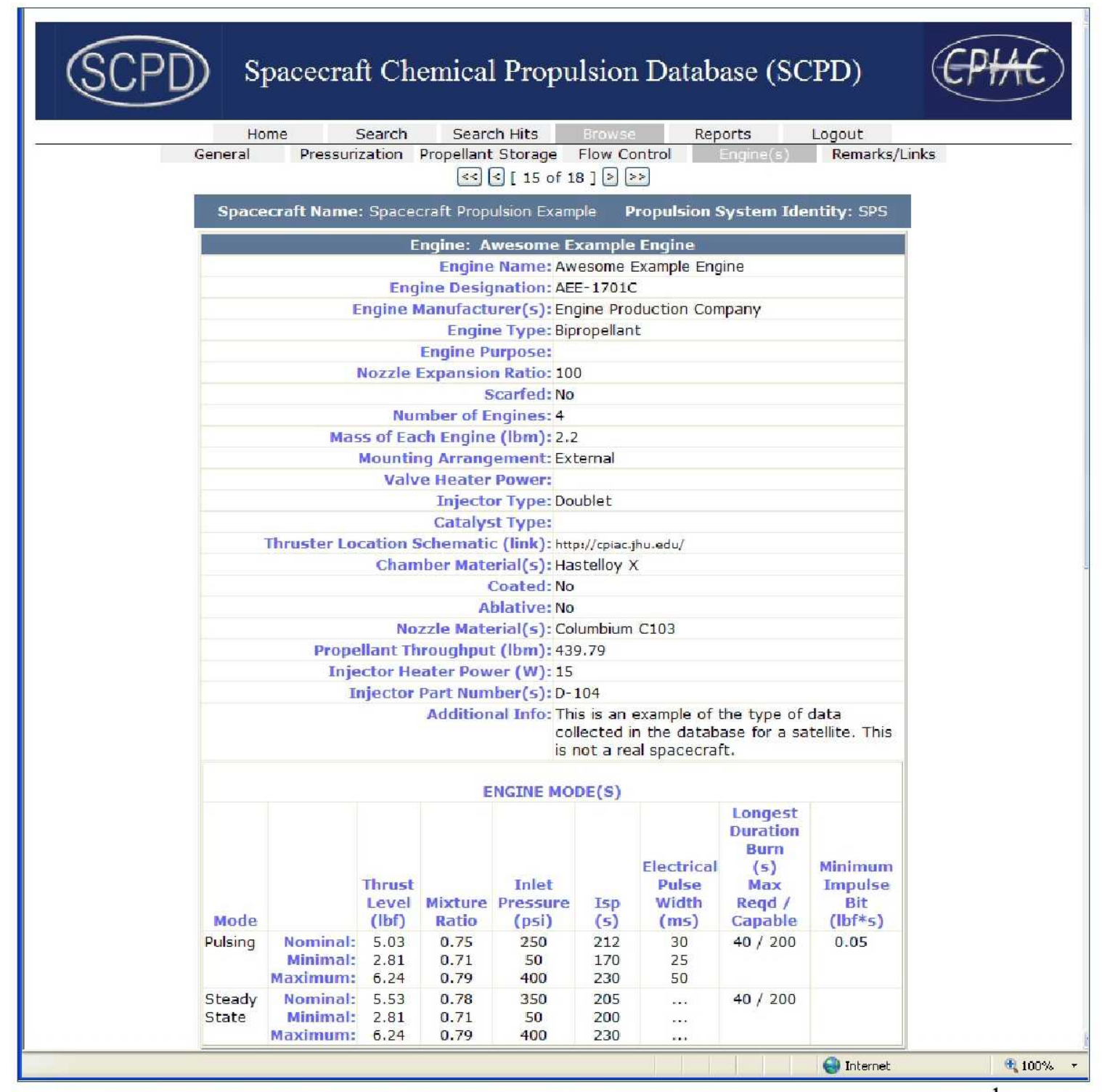

Figure 4. The SCPD Engine(s) tab showing example data from a notional satellite. ${ }^{1}$

The data for SCPD are collected from program documents and technical publications and are then validated by cognizant organizations. Whenever possible, schematics, design documentation, reference lists, and links are included in a spacecraft record. Often, the data in SCPD are provided by a participating organization that does not provide the supporting documents for use on SCPD. In these cases, the data are still compiled from critical design reports, design schematics, and other official documentation, and are approved for use in the database, but the documentation is not available for the user to download. There are also times when the supporting documentation, such as AIAA papers, has redistribution limitations in which cases a citation exists but the document is not available for download.

SCPD has the ability to produce data reports for the user. The reports are produced for download on demand in rich text format. There are currently three reports from which to choose. The search hits report produces a table of the selected filtered (or unfiltered) search hits page. The references report produces a listing of the citations for the selected spacecraft, separated by spacecraft. The data sheet produces a report providing all of the data from each browse sub tab, for each selected spacecraft, one after another. This is essentially a collection of all the information for the selected spacecrafts in a printable format. The first page of the data sheet for an example satellite is shown in Figure 5 . 


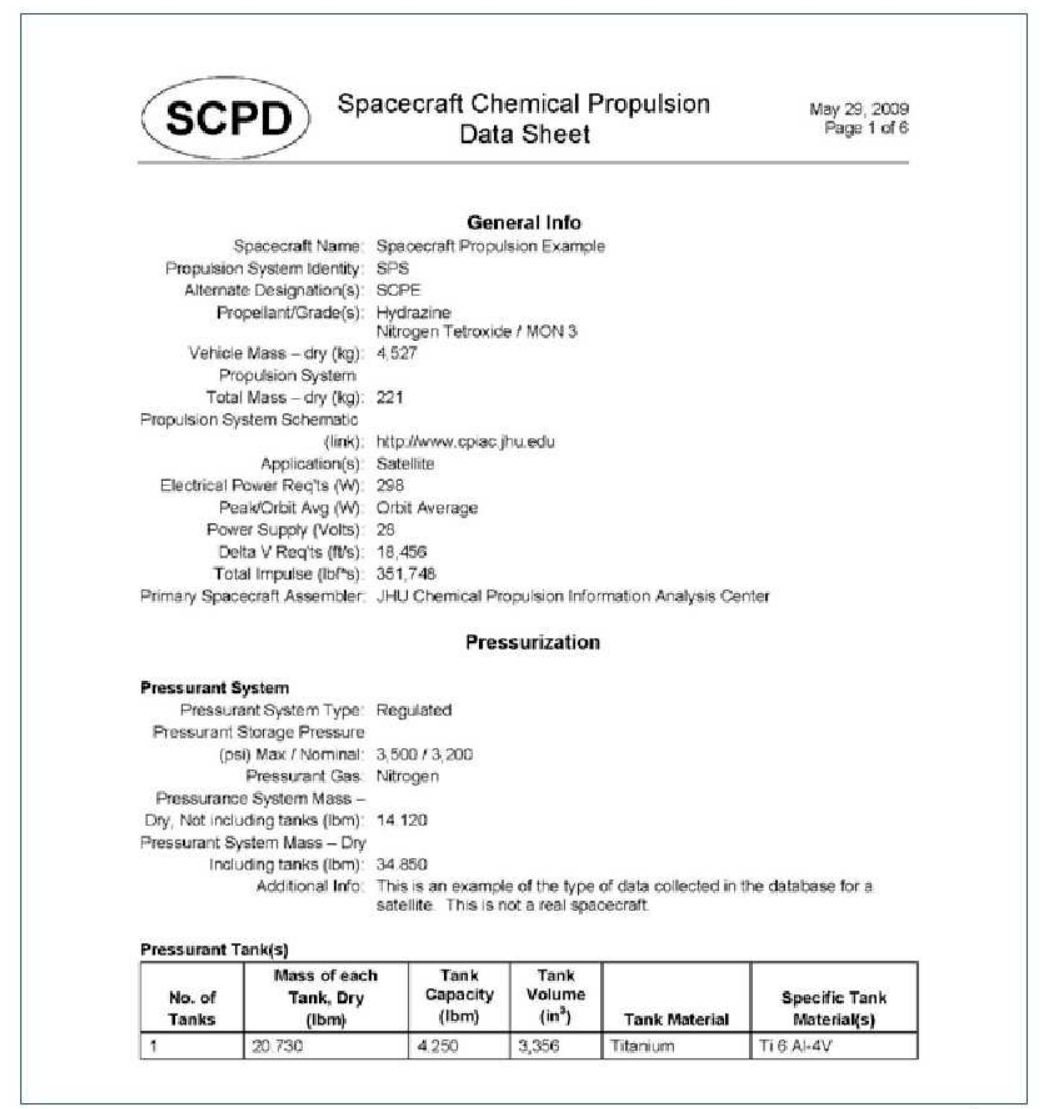

Figure 5. An example of the first page of a SCPD data sheet. ${ }^{1}$

With the data, documentation, and ability to produce reports on demand, SCPD allows a researcher to compare spacecraft, generate information for trade studies and mass estimates, and learn from what others have already experienced.

\section{Access to SCPD}

Access to the Spacecraft Chemical Propulsion Database is restricted to qualified U.S. citizens due to specific information that is restricted by International Traffic in Arms (ITAR) regulations or having been marked as distribution limited to U.S. Citizens who work for authorized U.S. Government agencies and their U.S. contractors. To access the database, go to http://cpiac.jhu.edu and click on CPIN Access [Login Required] under CPIAC Tools and Resources. If you're not registered, click on the "Sign up here" link under the login boxes. Select the Spacecraft Chemical Propulsion Database from the list, and fill out your information, payment information, and the additional information. Follow the instructions on the page. The CPIAC will contact you once your information has been verified. If you already have CPIN access, contact the CPIAC to request access to SCPD.

The Spacecraft Chemical Propulsion Database is compatible with Microsoft Internet Explorer. SCPD is copyrighted by The Johns Hopkins University and hosted by the CPIAC. The CPIAC is a U.S. Department of Defense (DoD) Information Analysis Center (IAC) within The Johns Hopkins University Whiting School of Engineering and sponsored by the Defense Technical Information Center (DTIC). IACs are part of the DoD's Scientific and Technical Information Program (STIP) prescribed by DoD Directive 3200.12 and are chartered under DoD Instruction 3200.14-E5. The CPIAC is the U.S. Government's designated repository for rocket propulsion information. The CPIAC can be contacted at 410-992-7300.

\section{Collaborative Efforts}

SCPD was made possible through the cooperation of various organizations who are participating members in both the American Institute of Aeronautics and Astronautics (AIAA) and the Joint Army Navy NASA Air Force (JANNAF) Interagency Propulsion Committee. The Chemical Propulsion Information Analysis Center produced 
the SCPD database structure based on information from the JANNAF Spacecraft Propulsion Subcommittee's (SPS) Chemical Propulsion Panel. Heading up this panel and the panel activity were Eric Cardiff of NASA GSFC and Pat McRight of NASA MSFC. Based on input from other panel members, they provided to the CPIAC an initial list of technical details they wanted captured in the database and the reasoning behind requesting the database. MSFC has contributed funds, data, data review, and additional support to the project. MSFC's data collection has been assisted by the University of Alabama at Huntsville. GSFC has contributed data, data review, and additional support to the project. DTIC provided additional funding for CPIAC involvement. The CPIAC produced multiple iterations of the database, each expanding upon the initial data fields into the comprehensive database as it stands today.

The JHU APL provided data input from their systems. The MSFC/GSFC/APL team assisted the CPIAC in providing input to the data fields and requirements for the database throughout the project. In the spring of 2009, NASA's Jet Propulsion Laboratory joined the team and began to collect information on their systems for addition to SCPD. All of these organizations participated in reviewing the data in SCPD, and they are continuing to contribute to SCPD. All efforts by participating organizations were performed under their own internal funding mechanisms. Various other organizations participating in the JANNAF SPS Chemical Propulsion Panel and the AIAA have also provided support and data for SCPD.

SCPD is an ongoing database project that continues to grow. Currently the database consists of spacecraft that were mostly government-funded projects. These spacecraft cover a wide variety of mission profiles, including Earth-orbiting scientific satellites, interplanetary spacecraft, upper stage systems, interplanetary Landers, transfer vehicles, and even human- rated spacecraft. As the collaborative effort continues, the propulsion systems of satellites used for telecommunication, defense, and other industry, university, and government applications are expected to be added. Organizations wishing to participate should contact the CPIAC.

\section{Example of Use}

SCPD has a variety of uses, including comparison of past systems and trade studies. Table 2 is an example of a comparison of three propulsion systems: Mercury, Gemini, and Apollo. If a user wishes to compare the propellants used on the Mercury, Gemini, and Apollo capsules, he or she could go to the SCPD database and perform a search. The user would select "Crew Transport" from the "Applications" selection on the search page. The resulting search hits would include Mercury's reentry control system, Gemini's orbit adjust and maneuvering system (OAMS) and reentry control system, Apollo service module's reaction control system (RCS) and service propulsion system (block II), Apollo command module's RCS, and Apollo lunar module's RCS, descent propulsion system, and ascent propulsion system. The user could click on browse and, by reviewing only the general tab for each system, could quickly and easily copy the information into a table as shown in Table 2.

Table 2. Comparison of Propellants from Mercury, Gemini, and Apollo

\begin{tabular}{|l|l|l|}
\hline \multicolumn{1}{|c|}{ Spacecraft } & \multicolumn{1}{c|}{ Propulsion System } & \multicolumn{1}{c|}{ Propellants } \\
\hline Mercury & Reentry Control System & Hydrogen Peroxide \\
\hline Gemini & OAMS & $\begin{array}{l}\text { Monomethylhydrazine } \\
\text { Nitrogen Tetroxide }\end{array}$ \\
\cline { 2 - 3 } & Reentry Control System & $\begin{array}{l}\text { Monomethylhydrazine } \\
\text { Nitrogen Tetroxide }\end{array}$ \\
\hline Apollo Service Module & $\begin{array}{l}\text { Service Propulsion System } \\
\text { (SPS Block II) }\end{array}$ & $\begin{array}{l}\text { Aerozine-50 } \\
\text { Nitrogen Tetroxide }\end{array}$ \\
\cline { 2 - 3 } & RCS & $\begin{array}{l}\text { Monomethylhydrazine } \\
\text { Nitrogen Tetroxide }\end{array}$ \\
\hline Apollo Command Module & RCS & $\begin{array}{l}\text { Monomethylhydrazine } \\
\text { Nitrogen Tetroxide }\end{array}$ \\
\hline Apollo Lunar Module & RCS & $\begin{array}{l}\text { Aerozine-50 } \\
\text { Nitrogen Tetroxide }\end{array}$ \\
\cline { 2 - 3 } & Descent Propulsion System & $\begin{array}{l}\text { Aerozine-50 } \\
\text { Nitrogen Tetroxide }\end{array}$ \\
\cline { 2 - 3 } & Ascent Propulsion System & $\begin{array}{l}\text { Aerozine-50 } \\
\text { Nitrogen Tetroxide }\end{array}$ \\
\hline
\end{tabular}

From there, the user would see that the Mercury spacecraft, being a monopropellant system, was less complex in design than the bipropellant systems of the Gemini and Apollo spacecrafts. The Apollo service and command 
modules' RCS systems used the same propellant combination as that of the predecessor Gemini spacecraft, but the Apollo lunar module (LM) and Apollo service module's service propulsion system (SPS) used aerozine-50 instead of monomethylhydrazine (MMH). If curious as to the reasoning, the user could click on the remarks/links tab and refer to the reference list for a starting point for his or her research. The reference literature shows that halfway through the SPS development program, data indicated a 3-5 second increase in specific impulse with an oxidizer-tofuel ratio of 1.6 using aerozine-50 over the previously designed 2.0 ratio using $\mathrm{MMH}$. The increased performance was desirable to provide for the LM weight growth and for additional flexibility in mission planning. The redesign was called the Block $\mathrm{II}^{2}{ }^{2}$ The small performance increase from using aerozine-50 was also desirable for the LM Ascent propulsions system, and due to a design philosophy of using common components wherever possible, all of the systems on the LM used the same propellants. ${ }^{3}$

\section{Conclusion}

The Spacecraft Chemical Propulsion Database is a new online central repository that provides the user with detailed spacecraft propulsion subsystem information and the ability to produce it in a report format on demand. This tool provides researchers with the capability for quickly and easily generating trade studies and mass estimates and to learn from the experiences of others. With a wide variety of spacecraft types in the database, the user can compare both similar and dissimilar propulsion systems to determine similarities and differences. Online viewing allows the researcher to easily log in and perform research from anywhere. Rich text format reports can be generated on demand providing the researcher with the data in a useful format for printing and copying into trade study tables, mass estimates, and reports. Design documentation and references, when provided, allow the researcher to delve even deeper into the study of propulsion systems of interest. Access to SCPD is controlled by the CPIAC and limited to U.S. Government agencies and their U.S. contractors. SCPD was developed through the cooperation of multiple JANNAF and AIAA participating organizations. The collaborative effort will continue to expand, more data will be added, and the database structure will continue to evolve as necessary to provide added value to the entire U.S. propulsion community.

\section{Acknowledgments}

SCPD effort owes its success to the cooperation of members of both the AIAA and the JANNAF propulsion communities. All of the support and participation in SCPD is greatly appreciated by all involved parties.

SCPD was made possible by funding from NASA MSFC and DTIC.

\section{Nomenclature}

$\begin{array}{ll}\mathrm{ft} / \mathrm{s} & =\text { feet per second } \\ \mathrm{kg} & =\text { kilogram } \\ l b_{f} & =\text { pounds force } \\ l b_{f}{ }^{*} s & =\text { pound force seconds } \\ l b_{m} & =\text { pounds mass } \\ m s & =\text { millisecond } \\ p s i & =\text { pounds per square inch } \\ s & =\text { seconds } \\ W & =\text { Watts }\end{array}$

\section{References}

${ }^{1}$ SCPD, Spacecraft Chemical Propulsion Database, Ver. 0.0.5, The Johns Hopkins University, Hosted by The Chemical Propulsion Information Analysis Center, Columbia, MD, 2009.

${ }^{2}$ Gibson, Cecil R., and Wood, James A., "Apollo Experience Report - Service Propulsion System," NASA Technical Note D7375, CPIAC Abstract No. 1973-1271, Lyndon B. Johnson Space Center, Houston, TX, 77058, August 1973.

${ }^{3}$ Owen, David B., II "Design Philosophies of Propulsion Systems of Early Manned Spacecraft," CPIAC Abstract No. 20090030, Chemical Propulsion Information Analysis Center, The Johns Hopkins University, Columbia, MD, 21044, March 2009. 